\title{
The Ethics of Pandering in Boston Public Schools' School Assignment Plan
}

\section{Citation}

Levinson, M. (March 2015). The Ethics of Pandering in Boston Public Schools' School Assignment Plan. Theory and Research in Education 13(1).

\section{Permanent link}

http://nrs.harvard.edu/urn-3:HUL.InstRepos:12991704

\section{Terms of Use}

This article was downloaded from Harvard University's DASH repository, and is made available under the terms and conditions applicable to Open Access Policy Articles, as set forth at http:// nrs.harvard.edu/urn-3:HUL.InstRepos:dash.current.terms-of-use\#OAP

\section{Share Your Story}

The Harvard community has made this article openly available.

Please share how this access benefits you. Submit a story.

\section{Accessibility}




\title{
The Ethics of Pandering in Boston Public Schools’ School Assignment Plan Meira Levinson
}

\begin{abstract}
How can access to public elementary schools of variable quality be justly distributed within a school district? Two reasonable criteria are (a) that children should have equal opportunity to attend high-quality schools; and (b) school assignment policies should foster an overall increase in the number of high-quality schools. This article analyzes Boston Public Schools' (BPS) new school assignment plan in light of these criteria. It shows that BPS' plan violates equal opportunity by giving middle-class families privileged access to existing high-quality schools. BPS arguably panders to more-advantaged families, however, in order to pull them into the system and deploy their economic, political, and social capital to increase the total number of high-quality schools. Is this ethically defensible? To answer this question, we need to develop an ethical theory of pandering: of privileging the interests and preferences of already unjustly privileged actors because the consequences tend to benefit everyone. Such a theory will need to be ethically pluralistic and weighted along a contextually sensitive continuum, rather than rendered in all-or-nothing terms.
\end{abstract}

\section{Keywords}

Educational ethics, equal opportunity, school assignment, pandering, non-ideal theory, case study, Boston Public Schools

How should access to public elementary schools be distributed within a school district? What are the characteristics of a just school assignment system? Ideally, of course, every child would attend a high-quality school that fully serves her needs, however those are defined/understood. ${ }^{1}$ But this ideal takes us outside the realm of distributive justice, since distributive justice is relevant only under conditions of scarcity. If every child has access to a school that is and will remain high-quality, then scarcity is eliminated and distributive justice is eliminated as a concern.

So let me ask instead: How should access to public elementary schools of variable quality be distributed within a school district? What are the characteristics of a distributively just school assignment system when some district schools are much worse than others?

These are questions that Boston Public Schools (BPS) faced when it attempted to reform its school assignment system in 2012-2013. ${ }^{2}$ The purpose of this article is to describe the "Home-Based Plan” BPS adopted in 2013, to evaluate it in light of two prima facie reasonable criteria of distributional justice around school access, and then to raise questions about the ethics of BPS' choices—and by extension, the ethics of public institutions more broadly—when these two criteria come into conflict. In particular, I will propose that two reasonable criteria for distributing access to schools of variable quality are: (a) that children should have equal opportunity to attend schools that are currently deemed to be high-quality; and (b) school assignment policies should foster an overall increase in the number of quality schools available in the district. I will argue that Boston's Home-Based Plan gestures toward the ideal of equal opportunity, but in point of fact is far more focused on the second goal of "growing the pie" of good schools, which it does by giving middle-class families privileged access to existing highquality schools in order to draw them into and keep them in the system. 
As I explain in further detail below, integrating schools and the district as a whole by class so as to reduce hypersegregation of poor children is an essential means of increasing school quality at scale. ${ }^{3}$ By giving middle-class families privileged entry into already high-quality schools, BPS helps those schools maintain their hard-won gains. It also incentivizes these families, who are now vested in the success of the Boston Public Schools, to use their inequitably large social, political, and economic capital on behalf of the district (for example, in fighting state-level budget cuts). In addition, middle-class families who enter the lottery and then are assigned a lower-quality school can sometimes be enticed to "take a chance" and take up their assigned seat with the goal of improving the school. Without the sense that they had a reasonable shot at being assigned a decent school, however, these families would likely have never entered the lottery in the first place. By preventing preemptive flight, BPS thus creates additional opportunities to woo privileged families to discover "hidden gems" and put their capital into strengthening a lower-quality elementary school. ${ }^{4}$

This unequal privileging of already-privileged families, however, raises important questions about the ethics of pandering: i.e., the ethics of privileging the interests and preferences of already unjustly privileged actors because the consequences tend to benefit everyone. What philosophical and policy judgments should we reach about the permissibility of pandering? When pandering is justified, should it be transparent or obscured? In the case of the Boston Public Schools in particular, is the level and type of pandering appropriate, too little, or too much?

\section{Boston's Home-Based School Assignment Policy: A Brief Primer}

Boston Public Schools' "Home-Based Plan,” which took effect in 2013 to govern assignments for the 2014-2015 school year, is a novel elementary school assignment policy. All children entering kindergarten (called K2) are assigned "baskets" of 10-18 elementary schools to which they can apply through a BPS-wide lottery. Families find out their basket of schools by inserting their home address into http://www.discoverbps.org/. Each family's basket includes all schools that are less than a mile away from where they live (their "walk zone"), the three citywide elementary schools, an Early Learning Center, and any elementary school that the child's siblings already attend. In addition, the basket must include at least two schools that have Massachusetts Comprehensive Assessment System (MCAS) test scores in the top 25\% in the city (Tier I schools), at least two more schools whose MCAS scores are in the top 50\% (Tier I or II schools), and an additional two schools with MCAS scores above the bottom 25\% (Tier I, II, or III schools). ${ }^{5}$ Families will have some of these schools already within their walk zone. Additional schools will be added based on proximity to the family's address; if a family has one Tier I, two Tier II, and one Tier III school in their walk zone, for example, then the closest additional Tier I school, and the next closest additional Tier I, II, or III school, will be added to their basket. Families' choices also include one or more “option” schools-meaning schools that are traditionally underchosen, because they're universally thought to be lousy, and hence very likely to have space to accommodate all applicants - to ensure that every child entering kindergarten (called K2) and above is guaranteed a seat at one of the schools in their basket. ${ }^{6}$ Figure 1 summarizes families’ basket construction.

INSERT FIGURE 1 HERE 
After touring schools in the fall, families have about a month to submit a rank-ordered list of the schools in their basket to one of the Family Resource Centers. There is no preference given to families who submit their choices earlier versus later during this "school choice time;" all families who meet the early February deadline are entered into the first round of the lottery. A computer then runs an algorithm to assign children to schools. Children who already attend the school, say because they lotteried into pre-K (called K1) the previous year, are guaranteed that they can remain. Siblings of current students have next-highest priority. After that, children are assigned in order of school preference and their randomly generated lottery number, with better numbers breaking ties. Families are not informed of their lottery number; rather, all these calculations are done by the computer. Families are simply informed of the final results in late March.

The assignment algorithm does not take into account demographic features of the children (e.g. in order to ensure race/ethnicity, gender, or income balance), nor does it control for distance from the school other than by the initial basket construction. All kindergarten seats are made available to be assigned in this initial round (except for those committed to K1 students staying in the same school); hence, popular schools are filled by the end of round one. Families who enter later rounds of the lottery, because they move to Boston during the spring or because they were unaware of, disorganized about, or overwhelmed by the process of entering the initial lottery, therefore have much more restricted school choices.

Families who do not like their assignment, or who did not enter the first round, can enter the lottery in round two. It operates just as round one did, except that there is also a "parent compacting" option, which enables groups of families to join together and enter the lottery for an underchosen school (i.e. one that still has a number of seats available) as a group. This is intended to make unpopular schools more attractive as groups of parents can commit to engaging in and improving the school together. It is also intended to stop families with the resources to do so from deciding to exit Boston Public Schools in favor of charter, parochial, or independent schools, or in favor of moving to another district.

Because it is so new, data are sparse. Families seeking a seat for the 2014-2015 school year-the first year under this new system-learned the round one results in mid-March 2014. $73 \%$ of families were assigned one of their top three school choices. As of September 2014, there was no information yet available about patterns in families' participation (e.g. who participated in round one versus later rounds versus not at all), in families' choices (e.g. who chose what schools), nor in the lottery results (e.g. whose choices were more or less likely to be satisfied).

\section{Equality of Opportunity and the BPS Home-Based Plan}

There are a number of different values at play in Boston Public Schools’ Home-Based school assignment plan. In this section, I explore one inarguably important value: namely, children's equal opportunity to access a high-quality education. A basic premise of most contemporary ethical theories (and of most Americans' intuitions) is that a child's family background should not determine his or her opportunities in life. Whether she comes from a rich or a poor family, one that has lived in Boston for generations or who just arrived last week, every child in Boston deserves an equal opportunity to realize success in college, career, and citizenship (and arguably many other goals, as well)—which means every child deserves an equal opportunity to a high-quality education. ${ }^{7}$

The Home-Based Plan promotes equality of opportunity most notably by limiting the correlation between neighborhood residence and school access. If students were assigned to 
schools solely on the basis of their home address, then "geography would be destiny." Wealthier, more informed, and better-connected families would rent or buy homes near highquality neighborhood schools. Poorer and/or less informed families, often especially new arrivals, would be consigned to neighborhoods that feed to poorer quality schools. The HomeBased Plan attempts to counteract this pattern. Although the plan relies on students' addresses to construct their baskets of choices, it also explicitly tries to realize the principle of equal opportunity by ensuring that every family has at least four high-quality schools (which I define as Tier I or II—schools in the top 50\% in the city), and at least six quality (defined as Tier I, II, or III) schools, in their choice basket. In this respect, even the most isolated and impoverished families can be confident that they will have the opportunity to list some high-quality schools on their lottery form.

The Home-Based Plan also, perhaps counter-intuitively, promotes equality of opportunity by limiting the overall number of schools that are in each family's basket. Under BPS' former school assignment plan, Boston was divided into three large geographic zones. Families could try to lottery into any school in their zone, any school within a mile of their house, and any citywide school. This gave families the "opportunity" to choose among 25 or even 30 elementary schools - a number and range of choices that could prove overwhelming even to the most informed and organized parents. As a result, parents with high levels of social capital organized both formally and informally to trade information about schools (and about techniques to game the lottery, until the algorithm was changed in 2006), while other families were forced to choose more blindly. By restricting families' choices to 10-14 schools, on average, the Home-Based Plan paternalistically increases potential equality of opportunity by making it more likely that all families can learn enough about the schools in their basket to make reasonable choices that reflect their true preferences.

At the same time, BPS' Home-Based Plan limits equality of educational opportunity in some significant ways. First, the Home-Based plan provides all families an equal minimum set of options, not an equal maximum. There is an equal floor: everyone has at least 4 high-quality (Tier I or II) schools in their basket, and at least 6 schools in their basket that are not of the lowest quality in the city. Even families who live far away from quality schools are therefore "leveled up" so that their minimum basket is equal to all other families' minimum basket. This is a common and often appealing form of equality. But notice that by not ensuring an equal maximum, or ceiling, the Home-Based plan still permits significant inequality in families' baskets of opportunities. Many families have only 4 high-quality schools in their baskets, while some families have as many as 7 high-quality schools in their baskets.

Second, simply being able to list schools for the lottery isn't really what opportunity is about. Opportunity is far more reasonably understood as one's chance of getting a seat in a high-quality school - which varies significantly depending on the size and competitiveness of the high-quality schools in one's basket. For example, in the 2013-2014 school year, 26 schools in Boston had 44 seats or less in K2, while 31 schools had 60 or more K2 seats. Differences in size can add up-as can the actual availability of seats. Full-inclusion schools, for example, may appear to have $22 \mathrm{~K} 2$ seats available, but actually be reserving 14 of them for students with special needs. Even more frustratingly, schools with pre-kindergarten (K1) programs may appear in prospective K2 families' baskets, but in fact have no available K2 spaces because the already-enrolled K1 students will rise up to take all the spots. Sibling priority may also radically reduce the number of seats open to new families. Hence, families that have the same number of 
quality schools in their baskets may have a 2-, 3-, or even 4-fold difference in the number of open quality seats in their baskets. ${ }^{8}$

Let's consider these disparities as they play out for two possible children: one living in the solidly middle-class neighborhood of West Roxbury; the other in the lower-income Dorchester neighborhood. West Roxbury has a child poverty rate of 5\%; Dorchester's child poverty rate is $29 \%$, nearly six times higher than West Roxbury's. I chose an address in each neighborhood, then used Boston Public School's on-line tool to get the basket of schools for a prospective regular education kindergartener (non-ELL, non-special needs) at each address. Let's call the West Roxbury kindergartener “Celia;” the child living in Dorchester we'll call "John.”

Celia ended up with 13 schools in her basket, including 6 high-quality schools—-three Tier 1, three Tier 2-with a total of 339 K2 seats. She has no Tier 3 schools in her basket because the six closest schools to her house were all in the top two tiers. Her basket does include, however, three "option” schools in order to guarantee she will receive a K2 seat assignment. John, by contrast, ended up with 14 schools in his basket, including only 5 high-quality schools - two Tier 1, three Tier 2-with a total of $268 \mathrm{~K} 2$ seats. He also has one Tier 3 and three option schools in his basket. ${ }^{9}$ Already, it is clear that John's family faces a slightly greater information burden and has access to $21 \%$ fewer high-quality seats than Celia does. Furthermore, a much higher proportion of the seats in his basket are in the bottom 50\% of BPS schools. Celia's basket contains 145 seats in option schools; John's basket contains 256 seats in Tier 3 and option schools. While John's basket is virtually evenly divided between seats in the top and bottom half of the school distribution, Celia's basket contains more than twice as many highquality seats as low-quality ones. ${ }^{10}$

These differences between Celia and John's formal versus substantive equality of opportunity are further exacerbated by the number of other children competing for the same K2 seats. Competition for seats is a function of the population density of young children living in the neighborhood, and their likelihood to enter the BPS lottery, both of which make John's already inequitable situation worse. As in any city, the population of the city of Boston is not spread evenly between neighborhoods. Lower-income neighborhoods are generally denser than middle- and high-income areas, with more people living in apartments than in houses, and with those dwellings close together on smaller lots. Also, some neighborhoods cater more toward families with school-age kids, while other parts of the city house more adults who are childless or whose children have grown. These differences in population age and density, along with differences in the size and location of high-quality schools, mean that competition for highquality school seats varies considerably across neighborhoods.

Returning to Celia and John, for example, the West Roxbury neighborhood has a population density of 700 young children (ages 9 or under) per square mile, while Dorchester's population density is triple that: 2135 young children per square mile. Because baskets are based on students' home addresses, meaning that children who live near each other will have the same basket of schools, this means that John is likely competing against three times as many children for the 268 high-quality seats in his basket than Celia is competing against for the 339 highquality seats in her basket.

Unsurprisingly, these competition disparities track both income and race. There are thirteen Boston neighborhoods with a young child density under 1500. These neighborhoods on average are $51 \%$ white, have a median income of $\$ 59,920$, and have a $21 \%$ child poverty rate. By contrast, the seven neighborhoods with a young child density over 1500 on average are 26\% white, have a median income of $\$ 41,855$, and have a $33 \%$ child poverty rate. Or, described 
another way, an average of 1162 children per square mile-about 59\% of whom are white-live in neighborhoods with a median income over \$50,000 per year. An average 1798 children per square mile-only $24 \%$ of whom are white-live in neighborhoods with a median income below $\$ 50,000$ per year. ${ }^{11}$ On average, therefore, low-income children of color are facing significantly stiffer competition for high-quality school seats than are middle- and upper-income white children in Boston.

If there were significantly more high-quality schools in low-income neighborhoods than in middle-class neighborhoods, then the greater availability of seats might offset this competition disparity. But as in virtually all U.S. cities, high-quality elementary schools in Boston tend to be clustered disproportionately in wealthier neighborhoods, not poorer ones. Fifteen high-quality schools and approximately 15,800 children ages 0-9, for example, reside in the nine neighborhoods in Boston that have a child poverty rate below 20\%. By contrast, the twelve Boston neighborhoods with a child poverty rate over $20 \%$ host a total of 22 high-quality schools - and 43,500 children aged nine and under. In the higher poverty neighborhoods, in other words, nearly three times as many children are competing for spots in only 1.5 as many highquality schools.

These statistics are all predictive rather than demonstrative of actual inequities in school access. Since 2014 school assignments have now been made according to the Home-Based Plan, it should be possible to analyze selection and assignment patterns and determine whether formal equality of opportunity (i.e. a leveled-up set of quality schools in everyone's basket) actually translates to substantive equality of opportunity (i.e. likelihood of gaining a seat in a quality school). In addition, it should be possible to run a simulation using BPS' lottery algorithm in order to analyze how the basket construction structures children's opportunities to access quality schools. Pretend that every child who entered the 2014 lottery preferred higher-tier schools to lower-tier schools, and within each tier, preferred closer schools to further away schools.

Aggregated simulations of the BPS lottery under these conditions would reveal whether children from different neighborhoods or income brackets truly do experience disparities in real access to quality schools or not.

Even before these analyses are conducted and made publicly available, however, there are obvious ways in which the baskets could be constructed so as to achieve more substantive equality of opportunity. Even keeping schools (rather than seats) as the distributive metric, BPS could “level down” by taking extra high-quality schools out of some families' baskets, and also potentially by inserting more low-quality schools into their baskets. This approach would equalize families' minimum and maximum opportunities to access quality schools. It would also equalize the burdens of gathering information on multiple schools, in this case by increasing the burden on previously more privileged families. Alternatively (or in addition), census data and/or prior school demand data could be used to calculate a competition index for school seats. K2 seats in schools with K1 programs could also be discounted given their likely unavailability to children not already enrolled at the school. Families' baskets could then be built so as to equalize seat-level competition rather than school access.

There are also ways to achieve more substantive equality of opportunity by revising the lottery algorithm itself. In San Francisco, children from neighborhoods with low average test scores (a sadly reliable proxy for income) are given weighted priority in the lottery. If this were applied in Boston, then even if low-income children have fewer and more competitive highquality schools in their baskets than middle-class children do, their likelihood of gaining a seat at a good school could be equalized. In Cambridge, “controlled choice” mechanisms ensure that 
every school reflects the broader socioeconomic demographics of the city. If the lottery results in a school that has a disproportionately high or low percentage of low-income children as compared to the system as a whole, then they are reshuffled (before the assignments are finalized) so as to ensure a more equitable distribution of children among schools — and more equitable distribution of schools among children. Again, this system could be used in Boston. In fact, BPS engaged in balancing procedures for many years to ensure that schools were racially and ethnically diverse, until it ended the policy in 2000-2001.

\section{Expanding Quality Schools: “Growing the Pie” by Reversing Middle-Class Flight}

These are very straightforward means of increasing substantive equality of opportunity for kindergarteners in Boston: Level families’ baskets up and down by capping the number of high-quality schools in a family's basket. Add more option schools to some families' baskets so as to increase their information burdens (which is another form of leveling down). Use quality seats rather than quality schools as the metric for building families' baskets. Give some priority in the lottery to children from low-income neighborhoods. Analyze the initial lottery results before they are released and adjust student assignments if schools seem inequitably distributed among families, or if families are inequitably distributed among schools. More complexly, use prior school choice and census data to calculate competition indices for schools or seats, and equalize baskets by competition index rather than by sheer number of seats or schools.

Should advocates for a distributively just school assignment system in Boston start advocating for these reforms? Not necessarily.

Leveling down approaches to equality are often bitterly opposed by those who would directly lose opportunities. It's one thing to agree that all Boston children should have some opportunity to lottery into high-quality schools. It's quite another to agree that one's own child should be denied the opportunity to lottery into a particular nearby high-quality school because other children across town don't have access to as many high-quality schools. This approach strikes many people as being merely punitive, or motivated by the "politics of envy," rather than as expressing a positive value such as equality. Now it's quite possible that this opposition to leveling down approaches is irrelevant as a matter of principle. It can be hard to justify a principle of equality that ends exactly where one's own sacrifice would begin. On the other hand, opponents of leveling down approaches might have principled reasons to oppose a concept of equality that tears down rather than builds up. Equality of opportunity may rightly be seen as an appealing principle insofar as it lifts up those with fewer opportunities, but not necessarily insofar as it wantonly reduces opportunities because some families have more than others. In this respect, it may be adequacy of opportunity, not equality of opportunity, that people truly embrace as a value.

Moreover, leveling-up weak equality (or adequacy) is likely to be compatible with a second commonsense feature of a just school assignment policy: namely, that it should foster an overall increase in the number of quality schools available in the district. The best—really, the only - way educational and social reformers know how to improve urban schools at scale is to eliminate hypersegregation of low-income children of color. Fifty years' worth of studies have demonstrated that children of all socioeconomic backgrounds tend to do better in lower-poverty schools; more recent studies have shown convincingly that school composition may even trump family background when it comes to academic achievement. The effects can be profound: lowincome children who attend low-poverty schools, for example, do better on average than middleincome students do in high-poverty schools. These patterns are replicated internationally. ${ }^{12}$ 
Furthermore, the magnitude of these school composition effects on the achievement of lowincome children may be larger than the magnitude of such within-school innovations as teacher hiring and firing, curricular shifts, data-driven instruction, lengthened school days, or other popular education reforms.

In particular, no other intervention in schools serving hypersegregated low-income students of color has proven replicable and reliable at scale. Although there are some highly touted hypersegregated schools, these are rare, often limited in their apparent achievement to the particular high-stakes standardized tests by which they are being measured, and challenging to replicate. A study of over 62,000 US public schools, for example, found that less than $1 \%$ of low-income schools ${ }^{13}$ —and only $0.3 \%$ of low-income schools serving over $50 \%$ students of color-achieved even decent academic results: at least two-thirds of students demonstrating proficiency on state standardized tests in two subjects, in two different grades, over two years. To be clear, this amounted to 39 academically acceptable high-poverty schools across the entire country in 1999-2000 (the year from which the data were drawn). This is compared to about a quarter of low-poverty and low-minority schools—or 10,174 schools across the United States (Harris, 2007) ${ }^{14}$ BPS elementary schools exemplify this persistent, stubborn relationship between hypersegregation and academic struggle. Tier I schools have a student body that is, on average, $28 \%$ white and $36 \%$ non-poor; option schools, by contrast, are on average $5 \%$ white and $16 \%$ non-poor. Similarly, only 3 out of the 18 Tier I schools have a student body that is over $80 \%$ low-income, while only 2 out of the 19 option schools have a student body that is under $80 \%$ low-income. ${ }^{15}$

Although a few hypersegregated charter networks-amounting to at best a few hundred schools across the country, including some in Boston-may now be achieving more consistent positive results than this, their academic achievements have proven difficult to scale within districts, with a full range of students, and along measures beyond state standardized test scores. Boston-area charters, for example, have been lauded as the most effective in the country and are also highly segregated. But they also serve radically lower percentages of ELL and special needs students; they have much higher attrition rates than the Boston Public Schools at virtually every grade level; they tend not to "backfill" with new students, so their student body becomes evermore selective; and their average SAT scores, while still significantly higher than Boston's, are far worse than one would predict given their MCAS scores, suggesting that they may teach to the high-stakes MCAS test rather than providing an overall superior education.

There are a number of reasons that schools that serve a critical mass of middle- and highincome students, as well as white students, tend to be higher quality. Such schools tend to have more parent involvement, fewer discipline problems, higher levels of homework completion, lower levels of both student and teacher mobility, higher percentages of children who enter school "ready to learn," fewer suspensions and expulsions, more extracurricular activities, more whole-child supports like guidance counselors and nurses, fewer interactions with law enforcement, fewer students who are battling homelessness or chronic illnesses, more experienced teachers, and larger per-pupil expenditures thanks both to regular budget allocations and to PTA fundraising (Orfield et al., 2014; Kahlenberg, 2012a; Orfield and Frankenberg, 2013).

Some of these school characteristics are due to the characteristics of the families themselves. Wealthier parents, for example, tend to have greater capacities to donate money to the PTA, to maintain more stable living situations, and to expose their children to academically enriching opportunities from birth onward. Many of these school characteristics are also due to 
the social, cultural, and political capital these families are able to deploy both within and beyond the school in order to serve their own children. For a variety of unjust but nonetheless politically and socially potent reasons, higher-income and white parents are more likely to be successful in lobbying officials to limit or reverse school budget cuts, for example, or to change a school policy that they believe is harming their children.

Nor do white and non-poor parents necessarily even need to deploy such capital, as their children are often pre-emptively served better by schools and districts. The cultural congruence between overwhelmingly white and middle-class educators' expectations and white and middleclass students' behaviors, for example, can create a virtuous cycle that nurtures academic achievement, teacher and administrator stability, developmentally-appropriate disciplinary policies, and other aspects of a strong and positive school culture. To say that socio-economic and racial integration is a key factor for improving schools at scale, therefore, is not to suggest that low-income children and families of color are intrinsically educationally deficient, nor that they intrinsically benefit from simply sitting next to middle-class and white children. Rather, it is to say that there are multiple, persistent, and significant instrumental benefits to having a critical mass of white and non-poor children in one's school.

To create lower-poverty schools, however, districts must actually attract non-poor families into the system - and equally importantly, not push middle- and higher-income families out of the system. Leveling up approaches are far more likely to attract and retain such families than are leveling-down policies that families interpret as a direct assault on their educational rights and interests. If leveling-down policies induced well-resourced families to exit BPS when they might have stayed under a leveling-up policy like the Home-Based plan, therefore, then that might be a good reason to trade equality of opportunity for adequacy of opportunity.

Boston has good reason to be concerned about white and middle-class flight. Unusually for the United States, where close to $90 \%$ of children attend public schools, only $74 \%$ of all school-age children living in Boston attend BPS schools. Of the approximately 20,000 Boston children who are not enrolled in BPS, about one-third attend charter schools, one-half attend parochial or other private schools, and $15 \%$ are bused to suburban public schools through the inter-district METCO program. Socioeconomic data are not available on all of these students, but the ethnoracial data are stark. Nearly half (47\%) of all white children and one-third (31\%) of black children living in Boston attend non-BPS schools, as compared to Hispanic (12\%), Asian (14\%), and other/multiracial (15\%) children. As a result of these patterns, $87 \%$ of children who do attend BPS are non-white, and about three-quarters are low-income (i.e. eligible for free or reduced price lunch). If more white and middle-class families living in Boston entered the lottery and then took up their school placements, then these demographics would look quite different.

Furthermore, many non-poor and white Boston families flee the city before their children reach school age. Every year, in fact, more than 2250 children under the age of 5 years move out of Boston (Reardon, 2012). Census data suggests that about half of those who migrate to or from Boston head from/to out of state. But the other half move within the state-many to surrounding suburbs. This may be because their growing families need more space, another bedroom, perhaps a back yard. But it may also be because their families seek educational reliability and predictability: they want to know where their children will attend school, and have some confidence that the school will be of good quality. Unsurprisingly, movement out of Boston is concentrated almost entirely among households with high levels of education and income. ${ }^{16}$ 
Families with economic means, therefore, hold a trump card with Boston Public Schools: that of threatened exit. BPS knows that privileged families will and do exit preemptively to the suburbs (often when their children are 2 or 3, in time for their children to integrate into their new neighborhoods well before the start of kindergarten). Furthermore, even if these privileged families remain in the city, they can and will exit into charter, parochial, and other independent schools, or into suburban districts via METCO. If BPS wants to convince such families to stay in Boston, enter the lottery, and then actually enter the school system, therefore, then it must offer inducements to such families not to engage in preemptive exit. These inducements include address-based basket construction, a lottery unweighted by demographic characteristics, absolute priority to first round lottery entrants, and the back-end reassurance of parent compacting. Taken together, these inducements offer privileged families some extra assurance that they will win rather than lose the lottery, and hence that it's worth sticking around to play the lottery in the first place. ${ }^{17}$

By inducing families to stay and play the lottery, BPS keeps high-quality schools integrated by race and class, thus ensuring that the schools are likely to remain high-quality. It also "grows the pie" by inducing families to enter the system even if they are assigned to a lower-quality school. Many Tier 3 schools, Boston officials argue, are actually "hidden gems" that feature committed teachers, families, and school leaders. Middle-class families who have invested time, energy, and hope in BPS — as indicated by their entering the lottery - may be convinced to embrace the "gem" to which they have been assigned, especially if they meet other middle-class families also entering kindergarten at the school. In this way, apparently lowerquality schools can become integrated within just a couple of years, and quality metrics change rapidly as a result. Such demographic shifts, especially when led by families who think of themselves as "saviors" of a school or as "urban pioneers," can be highly problematic. Even the most well-intentioned middle-class parents often exacerbate injustice by misrecognizing, marginalizing, and even excluding low-income families of color. These collective efforts are effective, however, at integrating formerly hypersegregated schools - and often therefore at raising test scores and other "objective” measures of overall school quality.

Finally, increasing the number of middle-class families in BPS can help the district as a whole, even if these families remain disproportionately concentrated in already high-quality schools, by mobilizing them to act on behalf of district-wide improvement. In Spring 2014, for example, several groups of BPS parents organized to increase city funding of Boston schools and to defeat statewide charter school legislation that could have cost BPS \$100 million or more. One parent group in particular-QUEST, which is substantially but not solely composed of middle-class BPS parents whose children attend disproportionately high-quality schools, and which coordinated efforts with other, more diverse grassroots organizations - was credited/blamed by politicians and activists on both sides for torpedoing the charter school legislation.

\section{Theorizing the Ethics of Pandering}

So, in pandering to privileged families, BPS reinforces unjust inequities of opportunity while creating the conditions for the system overall to increase in quality. The question arises, therefore: what are the ethics of pandering? In other words, what ethical principles should guide public policy when equal opportunity and overall well-being-including the welfare of the leastadvantaged - come into conflict with one another? I can't answer this question completely in this article, but let me offer up a few thoughts to move the theory forward. 
First, I want to clarify why this is a problem of pandering, and not one of either compromise or unjust coercion. BPS does not face a question about what compromises it should make because privileged families do not have a reasonable or legitimate claim that they can (or do) articulate about why their privilege should be maintained, let alone reinforced. Middle-class families themselves recognize this. They don't openly assert, "We should get priority in accessing quality schools because otherwise we'll leave,” as this is not a plausible claim as a matter of policy. Compromise seems to require competing articulable claims on both (or multiple) sides. School assignment policy in Boston does not involve such claims. On the flip side, it would also be unfair to say that just because privileged families have no defensible claims to special treatment, then their capacity to threaten exit must be unjust or coercive. The unequal power possessed by middle-class and higher income families clearly has unjust antecedents: varieties of racism, classism, xenophobia, and other forms of prejudice and discrimination; unjust capital flows and wealth accumulation; global inequities; and so forth. These inequalities are also undoubtedly perpetuated by contemporary structures and institutions that maintain historical injustice. Nonetheless, these families' use of their power to ensure that their children access quality schools is not in itself unjust. It is appropriate-perhaps even obligatory-for parents to do what they can to ensure that their children attend a decent school. ${ }^{18}$ They have BPS over a barrel, but not because they're behaving immorally. ${ }^{19}$

Second, an ethics of pandering hence must address a particular kind of normative question: not the bounds of acceptable compromise, nor the ethics of dealing with knaves, but rather the characteristics of ethically-defensible public policy-making in a presumptively fixed context of systemic injustice, where privileged individuals are nonetheless justified in acting in their own self-interest. Let me flesh this out a bit. Systemic injustice is presumptively fixed because policy makers can legitimately wrestle with whether or not to pander (and to what degree) only if they do not have the jurisdictional authority to tackle the background injustices head-on. If by contrast they could actually mitigate systemic injustices, then they should clearly do that rather than further reinforcing groups' unjustified privilege through inequitable treatment. The Boston Public Schools finds itself in the possible position of pandering, for instance, because BPS can revise school assignment procedures but cannot make policy that appreciably reduces family poverty or socioeconomic inequality writ large. That is why BPS is forced to decide whether to privilege already-advantaged families in allocating opportunities that under any just background conditions would be equiprobably distributed. The fact that pandering is about violating norms of equal treatment (and in particular, turning Rawls's difference principle on its head) is also why the ethics of pandering is about defensible rather than just policymaking. Pandering isn't just, but it may be the least-unjust policy available, and hence the most ethically defensible option given the circumstances. ${ }^{20}$

The ethics of pandering are confined to circumstances under which privileged individuals may properly act in their own self-interest because that's what makes pandering potentially normatively justifiable rather than merely strategically necessary. It's not about giving into unjust coercion but accommodating legitimate individual choices that are unfortunately made within an unjust context. That's not to say that these legitimate choices are the morally best choices. If every middle-class family in Boston with school-age children committed to BPS, for example, then BPS would instantaneously cease to be a high-poverty system. School quality district-wide would likely skyrocket (once expansion and funding challenges were sorted out), and both middle-class and low-income children would be more-or-less assured of attending at least a decent school. So collective commitment to BPS would be both normatively and 
empirically better than individualistic withdrawal to private and parochial schools or the suburbs. But in the absence of such a miraculous instance of collective action, privileged families are justified in opting out of low-quality BPS schools and into decent schools elsewhere, even though this action sustains and even exacerbates existing inequities. ${ }^{21}$

Third, I suggest that an analysis of pandering will have to be ethically pluralistic. Ethical pluralism is necessary because equality of opportunity may be a different kind of value-one that may rest on different fundamental ethical presuppositions - from the value of increasing overall social welfare by increasing the total number of quality schools. The former tends to rest upon ideals of democratic equality, civic respect, and/or individual rights. The latter, by contrast, is more consequentialist in orientation; what matters is the final outcome, that everyone have greater educational opportunity and access, rather than the relationship in which children or families stand with one another in the meantime. Although often these two sources of ethical judgment are considered to be either exclusive of or in hierarchical relationship to one another, I believe that a case like this demonstrates that in non-ideal contexts, at least, they each have a role in informing the same ethical policy analysis. ${ }^{22}$

Fourth, perhaps as a result, judgments about the ethics of pandering will inevitably be weighted along a contextually sensitive continuum, rather than rendered in all-or-nothing terms. It cannot be that "growing the pie" should always trump equality of opportunity to access highquality schools, no matter what the disparity in access. Nor, however, should equity always trump overall increase in quality. On the one hand, it has to matter that if pandering to alreadyprivileged families works to pull them into the Boston Public Schools, their infusion of economic, social, and cultural capital is likely to benefit many children. Increasing the welfare especially of the least advantaged (who are most likely to be enrolled in the Boston Public Schools) is a compelling claim of justice. On the other hand, it also has to matter that public policies that pander to already-privileged families are profoundly inequitable and simply reinforce existing, unjust inequities. This is perhaps especially true in an arena like education, where there is strong consensus that all children should have equal opportunities to learn. Public policies that distribute educational opportunities unequally to 5 year-olds, and especially that favor already-privileged 5 year-olds, seem simply unjust. Furthermore, insofar as it is virtually impossible for Boston Public Schools to admit publicly that their school lottery policies are designed to favor middle-class families, such lack of transparency is arguably profoundly civically disrespectful — especially toward low-income families who are already subject to so much civic disrespect, and who are now disproportionately losing in the school lottery to boot.

There is more work to be done before we can firmly answer either fundamental questions about the ethics of pandering in non-ideal policy contexts, or specific questions about the ethics of Boston's Home-Based Plan for school assignment. I do hope, however, that this case study enables a more careful and coherent debate about both, among philosophers, educators, policy makers, and citizens.

\section{Acknowledgments}

For feedback on earlier drafts, I would like to thank Andres Alonso, Harry Brighouse, AndréeAnne Cormier, Jacob Fay, Jennifer M. Morton, Anne Newman, Timothy G. Reardon, James Ryan, Christopher Winship, Megan Wolf, participants in the Spencer Foundation Philosophy of Education Institute in Chicago, and participants in the Radcliffe Workshop on Justice in Schools. I am also indebted to Kelly Dowd, Research Manager at the Boston Redevelopment Authority. This research was generously supported by a Milton Fund grant from Harvard University. 
Discussion of an earlier draft was supported by a grant from the Radcliffe Institute for Advanced Study at Harvard.

\section{Author Bio}

Meira Levinson is an Associate Professor at the Harvard Graduate School of Education and a Visiting Fellow at Nuffield College, Oxford, where she is working to develop a theory of educational justice with the support of a 2014-2015 Guggenheim Fellowship. Her latest book, No Citizen Left Behind (Harvard, 2012) has won awards in political science, education, social studies, and social philosophy. She has both taught and parented children in the Boston Public Schools for many years. 
Figure 1: Kindergarten Access Under Boston’s Home-Based Plan

Each child is assigned a customized basket of schools based on home address.

- Basket includes the closest:

- 2 Tier I schools (top 25\%)

- 2 next Tier I or II schools (top 50\%)

- 2 next Tier I, II, or III schools (top 75\%)

- Also includes all schools within one mile of home, citywide schools, siblings' schools, nearest Early Learning Center, and "option" (historically underchosen) schools

- Other schools may be included for ELL and Special Education

- Tiers currently based on a combination of MCAS proficiency and academic growth scores 
Boston Redevelopment Authority/Research Division (2014) Poverty in Boston. http://www.bostonredevelopmentauthority.org/getattachment/01cef762-956d-4343-a49ab41c280168ae/ (accessed September 12, 2014).

Boston Redevelopment Authority/Research Division (no date) Boston in Context: Neighborhoods. http://www.bostonredevelopmentauthority.org/getattachment/15ddcf065d87-4001-a255-70e55e011f19 (accessed September 12, 2014).

Cucchiara M (2008) Re-branding Urban Schools: Urban Revitalization, Social Status, and Marketing Public Schools to the Upper Middle Class. Journal of Education Policy 23: 165-179.

Cucchiara MB and Horvat EM (2009) Perils and Promises: Middle-Class Parental Involvement in Urban Schools. American Educational Research Journal 46: 974-1004.

DeSena JN (2006) "What's a Mother to Do?" Gentrification, School Selection, and the Consequences for Community Cohesion. American Behavioral Scientist 50: 241-257.

Harris DN (2007) High-Flying Schools, Student Disadvantage and the Logic of NCLB. American Journal of Education 113: 367-394.

Kahlenberg RD (ed) (2012a) Book The Future of School Integration. New York: The Century Foundation Press.

Kahlenberg RD (2012b) Turnaround Schools and Charter Schools That Work. In: Kahlenberg $\mathrm{RD}$ (ed) The Future of School Integration. New York: The Century Foundation Press, 283-308.

Kornhauser LA and Sager LG (1988) Just Lotteries. Social Science Information 27: 483-516.

Levinson M and Theisen-Homer V (2015) No Justice, No Teachers: Theorizing Less-Unjust Teacher Firings in L.A. Unified. Theory and Research in Education 13: forthcoming.

Mantil A, Perkins AG and Aberger S (2012) The Challenge of High-Poverty Schools: How Feasible is Socioeconomic School Integration? In: Kahlenberg RD (ed) The Future of School Integration. New York: The Century Foundation Press, 155-222.

Orfield G and Frankenberg E (eds) (2013) Educational Delusions? Why Choice Can Deepen Inequality and How to Make Schools Fair. Los Angeles: University of California Press.

Orfield G, Siegel-Hawley G and Kucsera J. (2014) Sorting Out Deepening Confusion on Segregation Trends. Los Angeles: The Civil Rights Project/Proyecto Derechos Civiles. http://civilrightsproject.ucla.edu/research/k-12-education/integration-and-

diversity/sorting-out-deepening-confusion-on-segregation-trends/Segregation-TrendsDispute-CRP-Researchers.pdf.

Posey-Maddox L (2013) Professionalizing the PTO: Race, Class, and Shifting Norms of Parental Engagement in a City Public School. American Journal of Education 119: 235-260.

Reardon T (2012) Comparative Analysis of Boston Public School Proposed Assignment Plans. http://www.mapc.org/sites/default/files/MAPC_BPS_AssignmentMemo_10_12_12.pdf (accessed April 9, 2014).

Thompson DF (1987) Political Ethics and Public Office, Cambridge, MA: Harvard University Press. 
${ }^{1}$ Note that I am bracketing all questions about how to define or recognize a high-quality school, whose judgment of quality matters (state vs. parent vs. child, e.g.), and how to take account of different judgments among actors. These questions are all essential to answer for a completelytheorized account of school access, but I believe they can be set aside for the purposes of this article.

${ }^{2}$ BPS also faced additional questions about educational justice in the context of substantial scarcity: in particular, what are the ethics of spending millions of dollars per year transporting children to school in the name of equitable access versus redirecting those funds into schools and classrooms in the name of increasing educational achievement? BPS spent over \$80 million in FY2013 on transportation, of which approximately \$30 million was allocated toward "controlled choice” busing of children around the city. Shifting entirely to neighborhood schools could have saved up to \$18 million per year-certainly a non-insignificant sum for a district struggling to meet some of its most basic educational obligations. I am grateful to Andres Alonso for pressing this point with me; for reasons of space, however, I will not consider the normative challenges related to spending money on school assignment vs. other district initiatives. I am also obviously leaving aside the actual politics of the school assignment reform debate in Boston.

${ }^{3}$ Although I focus predominantly on class in this article, ethnoracial integration is also important-particularly with middle-class whites-because of the unjust privilege that wealthier white families are accorded by school and government officials.

4 This account of middle-class families' positive influences on urban elementary schools and districts such as Boston requires two significant caveats. First, it would be absolutely fallacious to suggest that only middle- and upper-income families contribute to school improvement. Lowincome families in Boston and around the country work incredibly hard to support their own children's successes in school, their schools as a whole, and the district writ large. In Boston alone, for example, the Boston Parents Organizing Network (BPON), Union of Minority Neighborhoods, Greater Boston Interfaith, Boston Truth, and other groups are substantially organized by and work to mobilize low-income parents and community members, particularly parents of color. Similar organizations exist around the country, as do far less visible individual or small groups of low-income parents working passionately on behalf of their children, schools, and districts. Nonetheless, for reasons I discuss below, it is essential for school improvement at scale that middle-class families also be pulled into schools and districts. Second, it is important to recognize that middle-class families' work to improve schools and districts can often foster policies and practices that serve their own children's educational needs while leaving aside or even worsening other children's educational opportunities. Middle-class, especially white, parents who enter a "poor" school with the goal of "revitalizing” it also often end up misrecognizing low-income parents of color who have been committed to school improvement for years before the privileged "reformers" arrived. This can result in the marginalization of committed low-income parents and destruction of nascent or established initiatives designed to serve low-income students - in turn setting up the mechanisms that unduly privilege middleclass families' participation and interests in the future. See Cucchiara, 2008; Cucchiara and Horvat, 2009; Posey-Maddox, 2013; DeSena, 2006.

${ }^{5}$ For the first year, each school's MCAS average was calculated as a combination of absolute performance (counting for 2/3) and growth scores (counting for 1/3). Everyone agrees that standardized test scores are a very poor proxy for quality, and also that dividing schools up into rank-ordered quartiles impedes the district from demonstrating overall increases or decreases in quality. As of September 2014, therefore, the Boston School Committee is slated to vote on a 
new School Quality Framework that includes a wider array of measures. The new framework will also likely reverse the amount of weight given to growth versus performance in calculating each school's MCAS ranking.

${ }^{6}$ English Language Learners (ELLs) and children with identified special needs also have schools with appropriate services in their baskets as part of an "overlay" system. I do not address the overlays, nor hence the school choice options for ELLs and children with special needs, in this article.

${ }^{7}$ Rawlsians might modify this principle of equal educational opportunity to reflect the difference principle: the idea that inequalities in educational access might be permissible (or even required) in order to benefit the least well-off. However, insofar as Rawls argued that the principle of fair equality of opportunity is lexically prior to the difference principle, I am not convinced of this.

8 In Lewis Kornhauser and Lawrence Sager's (1988) terms, BPS' Home Based lottery is impersonal but not equiprobable.

${ }^{9}$ Celia's and John's baskets each also include the three city-wide schools and an Early Learning Center (ELC), which has no quality ranking because there's no MCAS testing below third grade, and ELC's end at second grade. I'm leaving these schools out of the analysis since they appear in all children's baskets equally. John's $14^{\text {th }}$ school is a regional school, also with no quality ranking, so I can't include it in the analysis.

10 John's challenges become even greater once we account for K1 students already in the school who will enter K2 at the same time as John and Celia. Out of the 268 high-quality K2 seats putatively available to John, only 65 are not already guaranteed to current K1 students. By contrast, out of the 339 high-quality K2 seats putatively available to Celia, 140 are still available once all current K1 students have claimed their K2 seats. Judging from an analysis I conducted of the K2 minus K1 seat availability in BPS schools by demographics, this seems to be an artifact of the addresses I chose, however, rather than a pattern predictable by neighborhood demographics.

${ }^{11}$ All data retrieved from or calculated on the basis of other data provided in Boston Redevelopment Authority/Research Division, 2014; Boston Redevelopment Authority/Research Division, no date.

12 This research is well-summarized in Kahlenberg, 2012b. See also Mantil et al., 2012.

${ }^{13}$ Defined as having a student body that is over $50 \%$ low-income. If truly hypersegregated schools were studied, therefore, with $80 \%$ or more low-income and/or students of color, the results would look even worse.

${ }^{14}$ Note that the article gives the number of total schools in each demographic category and percentage of each category that are high achieving; I used this data to calculate the number of high achieving schools with each demographic.

${ }^{15}$ Calculated using 2013-2014 school profile data from the Massachusetts Department of Education: http://profiles.doe.mass.edu.

${ }^{16}$ This was calculated using the Census Bureau's new Census Flows Mapper, http://flowsmapper.geo.census.gov/flowsmapper/map.html. Migration flows into Boston from surrounding counties among very low-income households, but switches direction out among higher-income households, and rises inexorably by income.

${ }^{17}$ In this respect, it will be interesting to find out what percentage of families in Boston with kindergarten-eligible children chose to enter the lottery in 2014 under the Home-Based Plan, as compared to previous years. 
${ }^{18}$ This is quite different from claiming that parents should do what they can to ensure their children attend the best possible school. For a variety of reasons, including those having to do with equal opportunity and "growing the pie" so that all children have a greater chance of attending quality schools, I believe that parents should ensure their children attend a decent school—one that surpasses a threshold of quality—but not necessarily more.

${ }^{19}$ That being said, it's possible that pandering begets further pandering, such that what starts out as a tool to improve schools becomes an end in itself to maintain one group's systemic advantage over another. This is certainly what some of the sociological literature cited in note 4 seems to suggest. I am grateful to Jim Ryan for pressing this point.

${ }^{20}$ Victoria Theisen-Homer and I discuss the characteristics of least-unjust policy-making in more detail in Levinson and Theisen-Homer, 2015.

${ }^{21}$ In this case, however, Boston's already high real estate prices would likely skyrocket, further pricing poor families out of the city. BPS could then be a victim of its own success, turning into a hypersegregated system for middle- and upper-class children, with poor families pushed out to inner- and outer-ring suburbs. In this case, systemic inequities could be further exacerbated rather than ameliorated. I am grateful to Chris Winship for raising this point.

${ }^{22}$ Dennis Thompson made the same point 25 years ago: "Instead of trying to decide between consequentialist and deontological moral theories, for example, [political ethics] uses the dispute between them to demonstrate the need for some different, more political, ways of assessing officials and their decisions” (Thompson, 1987: 8). Unfortunately, philosophical analyses and case studies of public decision-making, including educational decision-making, seem not to have caught up to his insight. 